\title{
Possibilities and Challenges of Online Education in India During the COVID-19 Pandemic
}

Souvik Sengupta, Aliah University, India

\begin{abstract}
The undergraduate and postgraduate studies of colleges and universities in India have been affected badly amidst the lockdowns for COVID-19 pandemic. The government has insisted to start the academic activity through online platforms. The biggest concern for the academic institutions now is to select an appropriate e-learning platform. This paper compares different features and facilities available in some widely used online platforms and analyze their suitability from the perspective of socio-economic constraints of students in India. A generic framework for conducting online classes is described that meets the special requirements of the unprivileged students. Some strategic plans to overcome the challenges are identified and suggested. A technical solution for implementation of time-bound assessment module is also proposed.
\end{abstract}

\section{KEYWORDS}

COVID-19 Lockdown, Higher Education, Live-Meetings, Mobile Application, Online Education, Time Bound Assessment, Virtual Classroom

\section{INTRODUCTION}

Since the first COVID-19 case reported in India on $30^{\text {th }}$ Jan 2020, the country has seen 44,22,021 confirmed cases, 34,39,814 recovered cases, and 74,484 death cases (MoHFW (Ministry of Health and Family Welfare, n.d.), as on $9^{\text {th }}$ Sep 2020). Starting from $25^{\text {th }}$ March 2020, the Government has imposed four consecutive lockdowns which spanned over 61 days and currently it is being withdrawn phase by phase. India operates mainly in semester education system for undergraduate and post graduate programs. At the time of starting lockdown, most of the programs were at the mid of the semester, thus the last semester was completed in a hurried unstructured way with mix of different online strategies, mostly using E-mail and WhatsApp. Now, the current semester has just begun and the teachers have got ample opportunity for planning and developing learning contents. Therefore, a suitable learning platform selection is currently the top priority for all the Colleges and Universities.

The selection of appropriate Learning platform must be driven by the fact that the pedagogy must be shifted from teacher-centric education to learner-centric education (Sathish et al., n.d.). It is evident from different studies that COVID-19 lockdowns have an adverse effects on the education sector and Indian students particularly from remote areas and marginalized sections are facing enormous challenges related to unavailability of smart-phone and computers, poor internet bandwidth, and unfavorable study environment at home(Kapasia et al., 2020)(Sintema, 2020). Therefore, there is always a need for Government intervention to set up a uniform academic plan for the universities and colleges regarding online education during this COVID-19 lockdown. A contingency plan is

\section{DOI: 10.4018/IJWLTT.285567}

This article published as an Open Access article distributed under the terms of the Creative Commons Attribution License (http://creativecommons.org/licenses/by/4.0/) which permits unrestricted use, distribution, and production in any medium, provided the author of the original work and original publication source are properly credited. 
required to deal with any possible discrimination among aspiring students for online education (Bao, 2020). However, online education is not new in India. Some universities successfully run 'dual mode' programs using common MOOC implementations (Farrow, 2019).Many Universities have also brought in courses from SWAYAM online platform into the curriculum to enhancing outcome based learning(Indian National Commission for Cooperation With UNESCO Response to COVID 19 , n.d.). On the other hand, some Universities provides e-Learning through LMS where focus is on assisting teachers in the management of their course, developing quality content, providing hands-on experience to strengthen skills, and arranging live and interactive sessions for question-answers and doubt clearance(Phutela \& Dwivedi, 2020)(Ouadoud et al., 2016). With the reduced cost and enhanced quality of 'software as a service' (SaaS) based e-learning tools and virtual classrooms, more and more Institutions are now offering courses on online platform(Aberdour, 2011). The sudden compulsion due to COVID-19 lockdown has now triggered the search for selecting appropriate e-learning platforms for colleges and Universities many of whom are not even ready for online education. Institutes also need to be aware of their ability to continuously monitor the quality of the learning contents and students' outcome (Crawford et al., 2020).

Considering the above scenario, this paper investigates the possibilities of starting online education in India using popular e-learning platforms. The author has considered only the free platforms for virtual classroom and online meetings. Though all of the products discussed here, have a commercial version which includes paid features, those are not included in this study. Only the essential features are discussed here which are the minimum requirements for starting online classes.

\section{A GENERIC FRAMEWORK}

Figure 1 describes a generic framework for core components or essential features which are commonly available in any online learning platform. These features can be grouped into two categoriesasynchronous set and synchronous set. In asynchronous set students can access the features at their convenient time, whereas in synchronous set students and teacher has to be present online at the same time. Generally teachers first create a virtual classroom and arrange the learning contents modulewise. They can also put assignments at the end of each module. Teachers can ask students to join the class by sending an invitation link to their mail ids. Once joined, student will always automatically get notification whenever anything is posted in the classroom; teachers need not to send mail to them. Teachers can use multimodal data as the medium of learning contents, like word documents, pdfs, power points, spread sheets, video lectures, and link of any web resources. Students can explore these contents at their own pace and time. However, teachers may prefer different strategies of publishing learning contents. Some prefer contents should be given before the live session so that they can use the live sessions for doubt clearance. On the other hand, some teachers prefer to give live lectures first and then the materials are given for further study.

In synchronous sessions teachers take live classes for their students. Normally, teachers schedule a meeting event and post the invitation in the classroom. All the students need to join the meeting at a particular time preferably with audio-visual input arrangement. Teachers can also record the live session partially or completely provided she has enough cloud memory space. The most important feature in this live session is the sharing of screen by the teacher. This enables the teacher not only to deliver a presentation using power point or word processor but also the teacher can demonstrate handson on the topic using simulators or any other online tools. This feature allows even some practical classes to be conducted within online platform if the lab sessions can completely be performed on computer systems. Taking attendance of students is another important requirement in live classes. Teachers should be able to export or download attendance in spread sheets.

A survey is conducted to understand the readiness and challenges of online education among the students of a state sponsored University at Kolkata, India. The findings are analyzed next. 


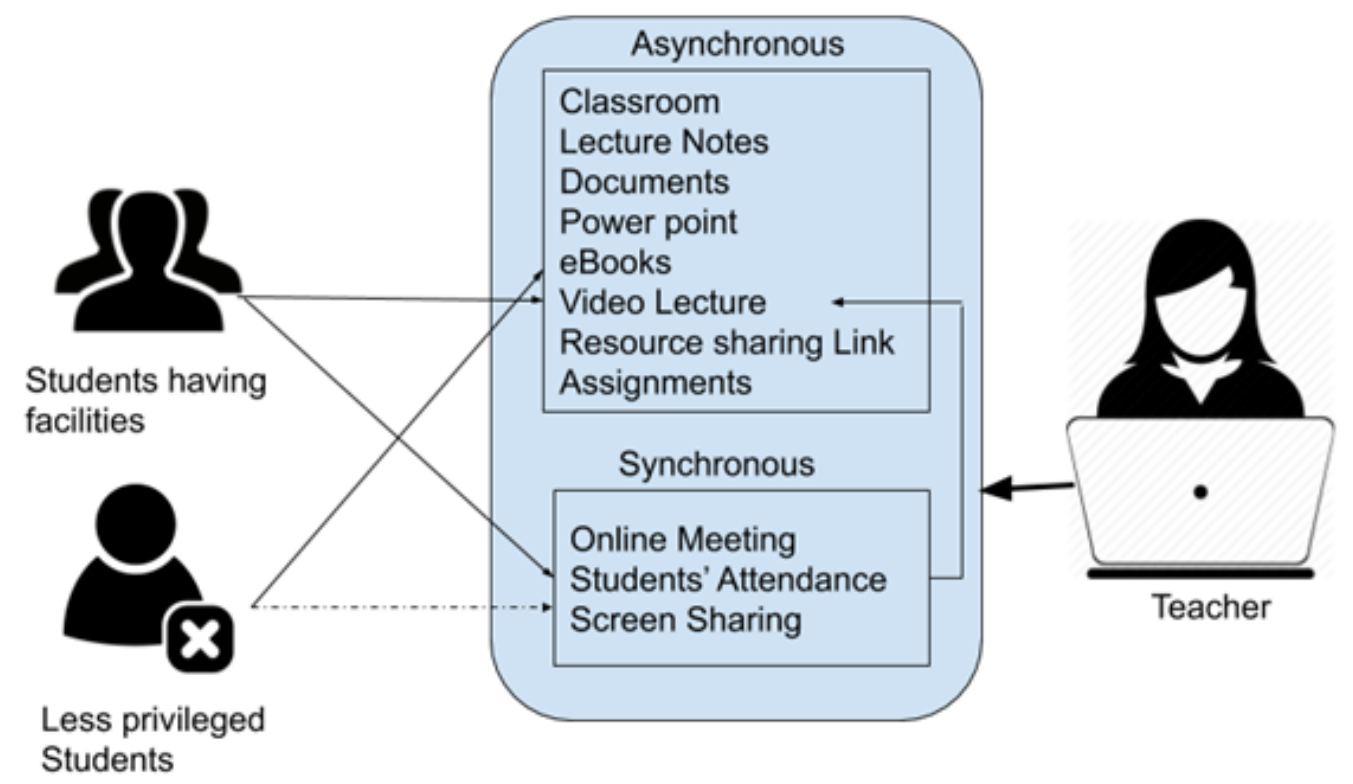

\section{THE SURVEY}

Most of the e-Learning platforms can provide the above mentioned core features. The primary question is whether students in India are in a position to adopt those technologies. Since $67 \%$ of the Indian population lives in rural areas (World Bank's United Nations Population Division's World Urbanization Prospects, 2018), students may have their own struggles in accessing these online platforms. The reasons are multifaceted, starting from financial constraints, inaccessibility of internet, devoid of smart phone, laptop or computer, up to unavailability of physical space (Kapasia et al., 2020). To have an understanding on how ready the students are for online courses, a survey is conducted on the students of a state sponsored University (aliah.ac.in) to find out the status of facilities that they could effort if online classes are offered. Although the sample is not taken across different Institutions across the entire country, it can be considered as an indication of what students from other Indian states are also facing. The sample questionnaires are as follows:

- What is your preferred device for online class? Smartphone/Laptop/Desktop

- What type of connectivity you would use? Mobile Data/Wifi/Broadband

- How good is your network traffic with respect to live streaming? Good/Moderate/ Slow

- What is your convenient time for attending live classes? Day Session/Evening Session/ Anytime

The survey form was sent to total 2152 under graduate and post graduate students of the University. However, 47 students informed that they could not effort any type of online education as they do not have any smart phone, laptop or desktop computer at home. Figure 2 depicts the results as obtained from response of 2105 students. Students participated in the survey are a good mix of representation from urban and rural areas and currently most of them are confined at their native places due to lockdown. The choice of preferred device is either Smartphone or laptop in most of the cases, which implies that the e-Learning platform must have android app as well as web version. The biggest challenge 
Figure 2. Students' technical facility status

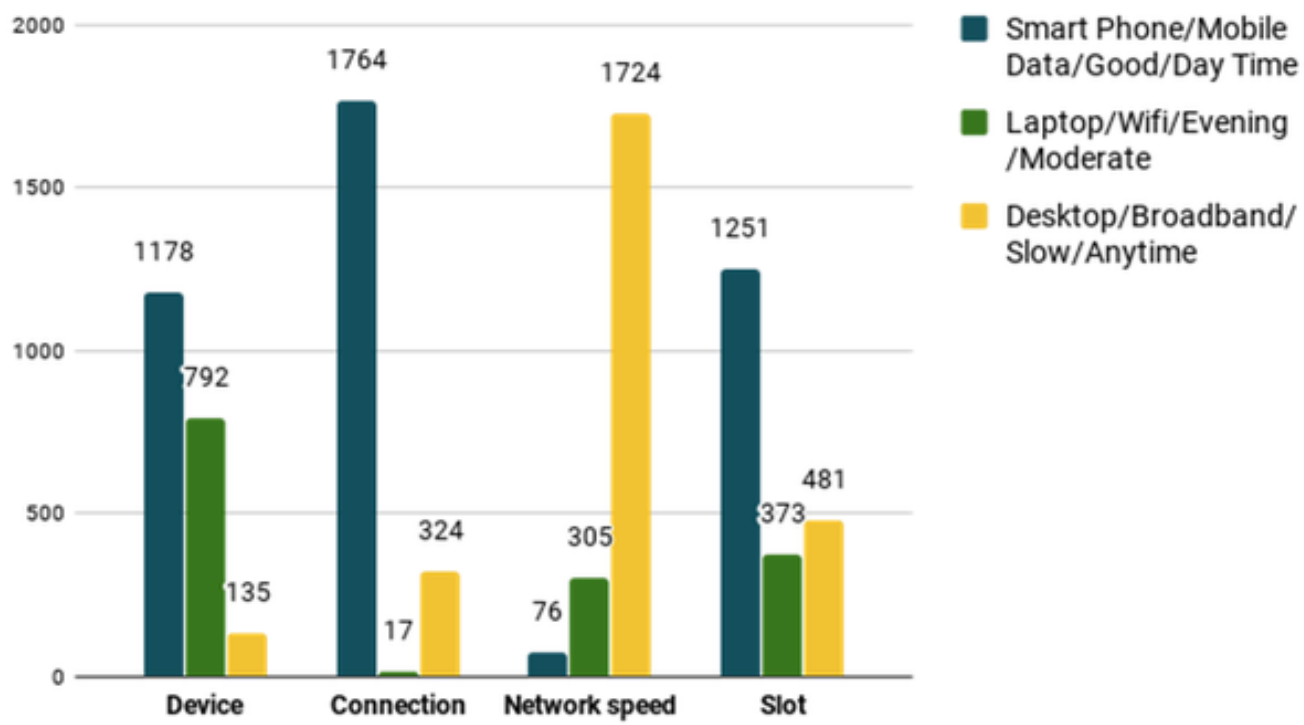

which is apparent from the data is that, most of the students are dependent on mobile data to access internet and the bandwidth is in general low. This would definitely hinder the live classes. Therefore, strategic planning is required so that classes should not depend too much on the live sessions. One solution could be, teachers can record the live session partly or completely and then put the link of the video to the respective class, so that students can view that at their convenience. The feedback for preferred slots from the students is also inconclusive. While the majority of the students preferred day sessions, a good amount of students also requested for evening session. The main reason behind their preferred choices are informed as frequent power cuts in their locality at particular times and also network bandwidth differs at different times.

Considering the above mentioned situation, the primary questions that are coming out from this study are:

1. How to ensure minimum technical facilities for all the students?

2. How to design classes so that students can utilize most of it?

3. What could be the modality to perform continuous evaluation of learner's progress?

4. How to evaluate students with time-bound assessment/evaluation?

In the next section, a comparative analysis is made on some of the commonly used e-Learning platforms namely G-Suite for education, Cisco Webex, Microsoft Team, Moodle and Zoom.

\section{COMPARING ONLINE PLATFORMS}

\section{G-Suite}

G-suite for education is a package that comes with multiple Google applications which are useful for taking online classes. Products include Google Classroom, Meet, Google Drive, Google Docs, Gmail, 
Google Calendar etc. The G-suite for Education is free of cost for accredited educational Institutes. For online meetings, built-in support is available through Google Meet.

\section{Microsoft Office 365}

Office 365 Education package is also free for educational Institutes. It comes with applications like Word, Excel, PowerPoint, OverDrive etc. Microsoft Classroom can be used by the teachers for online teaching and students can be engaged through Teams, OneNote, and email services. Online meetings are supported through Teams.

\section{Moodle}

Moodle is a complete LMS software designed for enabling Teachers, Administrators and Learners with an integrated system to create and use customized learning environments. The software can be downloaded free of cost and needed to be installed and configured onto the Institutional web server before using. There is no default online meeting tool for Moodle but other meeting tools like Zoom or Webex can be easily integrated.

\section{Zoom}

Zoom is an online meeting application which can be used for online classes. It comes with many useful features like content sharing, real-time co-annotation, and digital white board. Zoom also supports integrations with most of the popular LMS like Moodle, Canvas, Sakai, and Blackboard. There is also provision of taking attendance of the students using reporting tool.

\section{Cisco Webex}

Webex is primarily a video conferencing tool which is now also widely used for online teaching. It supports many useful features like file sharing, screen sharing, and white-boarding. There is also provision for personal rooms that serves teachers to mange resources and start meetings instantly or by prior scheduling.

This work categorizes the main two components of online learning, namely virtual classroom (asynchronous mode) and live meetings (synchronous mode), and compare how different products support the essential features.

\section{ANALYSIS OF THE PRODUCT FEATURES}

Table 1 and Table 2 show comparative analysis of features on popular e-leaning products for virtual classroom and live meetings respectively. Google Classroom and Microsoft Classroom come as Software as a Service (SaaS), which adds flexibility by avoiding buying, installing and maintaining the software (Aberdour, 2011). On the other hand, Moodle is freely available for download and installation, which incorporates added technical hazard of maintaining the software. However, Moodle is open source and highly customizable and can be integrated with most of the e-Learning tools, which is not possible in SaaS model. In terms scalability, Google Classroom and Microsoft Classroom are way ahead as they support 1000 users per class, and unlimited cloud storage. On the other hand, number of users and storage capacity in Moodle depends on the architecture on which it is deployed; therefore scalability cost is much higher in Moodle. Both Google and Microsoft classrooms can also be accessed via mobile apps, whereas Moodle can be accessed from phone via browser.

In case of live meetings, Google Meet and Microsoft Teams have identical features, except whiteboarding and attendance recording which are by default available in Teams but available through plug-in in Meet. Both of these products allow 250 participants and meetings remain valid for 24 hours. In contrast, free version of Zoom and Webex allow maximum 100 participants and meeting session of 40 and 50 minutes respectively. Since Meet and Teams are part of packages they are integrated with 
Table 1. Features of Virtual Classroom in different products

\begin{tabular}{|l|l|l|l|l|l|l|}
\hline Product & $\begin{array}{l}\text { Deployment } \\
\text { Model }\end{array}$ & Max No. of users & $\begin{array}{l}\text { Posting and sharing } \\
\text { learning contents }\end{array}$ & Assignments & Assessments & $\begin{array}{l}\text { App } \\
\text { Support }\end{array}$ \\
\hline $\begin{array}{l}\text { Google } \\
\text { Classroom }\end{array}$ & SaaS & 1000 & Yes & Yes & Yes & Yes \\
\hline $\begin{array}{l}\text { Microsoft } \\
\text { Classroom }\end{array}$ & SaaS & 1000 & Yes & Yes & Yes & Yes \\
\hline Moodle & $\begin{array}{l}\text { Download and } \\
\text { Install }\end{array}$ & $\begin{array}{l}\text { Depends on } \\
\text { Architecture }\end{array}$ & Yes & Yes & Yes & No \\
\hline
\end{tabular}

respective virtual classrooms, whereas Zoom and Webex are needed to be integrated with LMS like Moodle, Canvas etc. However, screen sharing feature is available in all the above mentioned products.

It is apparent from the above technical analysis that subscription to packages like G-Suite for Education or Microsoft Office 365 is better choice for Institutions where technical manpower to handle and monitoring LMS platform is not available. Google platform (Classroom and Meet) is slightly advantageous over Microsoft platform (Office 365 and Team) as the difference between enterprise edition and free version is minimal on G-Suite for Education. However, minimum internet facility and device support is a necessary prerequisite for all these services. The main limitation in all these platforms is the absence of any time-bound assessment tool which can work both in online and offline mode as per learner's convenience. Therefore, considering the questions narrated in section 3 , the following plans are suggested.

1. Government must make necessary arrangement for students who are without any Smartphone, laptop, PC, or internet connection, so that they can get access to computer at least for 2 hours per day.

2. The learning pedagogy should be shifted from 'Teacher-centric' to 'Learner-centric'. Teachers may post learning materials beforehand so that students can look through it before coming to live-class. This would enable the teachers to use the live sessions more towards doubt clearance and interactions than delivering lecture.

3. Teacher can provide assignments for each module in an incremental way. Students can submit a new assignment only after clearing the previous assignment.

4. For time-bound assignments/ examinations, a new android based assessment tool is required to support students both in online and offline mode.

Table 2. Features of Live meetings in different products

\begin{tabular}{|l|l|l|l|l|l|l|}
\hline Product & $\begin{array}{l}\text { Users } \\
\text { limit }\end{array}$ & $\begin{array}{l}\text { Time } \\
\text { limit }\end{array}$ & $\begin{array}{l}\text { Screen } \\
\text { sharing }\end{array}$ & $\begin{array}{l}\text { Default White } \\
\text { Board/ Plug-in }\end{array}$ & $\begin{array}{l}\text { Integration } \\
\text { with LMS } \\
\text { required? }\end{array}$ & $\begin{array}{l}\text { Meeting } \\
\text { Attendance }\end{array}$ \\
\hline Meet & 250 & $24 \mathrm{hrs}$. & Yes & Plug in- Jamboard & No & Yes (plug-in) \\
\hline Teams & 250 & $24 \mathrm{hrs}$. & Yes & $\begin{array}{l}\text { Default- } \\
\text { Whiteboard }\end{array}$ & No & Yes \\
\hline Zoom & 100 & 40 mins. & Yes & $\begin{array}{l}\text { Default- } \\
\text { Whiteboard }\end{array}$ & Yes & Yes \\
\hline Webex & 100 & 50 mins. & Yes & $\begin{array}{l}\text { Default- } \\
\text { Whiteboard }\end{array}$ & Yes & Yes \\
\hline
\end{tabular}


In respect to the first proposal, there is a need to perform an exhaustive survey to estimate the total number of students who may require such help. All the University and Colleges can perform this on behalf of the Government. Then Government initiatives can be taken to set up study centers at each block of each district to provide computer facility to the unprivileged students nearer to their homes. During the counseling process of under graduate Engineering entrance this year, different state governments in India have set up large number of help centers with computer and internet facilities in remote areas. In the state of West Bengal, more than 17000 of such centers have been established (wbjeeb.nic.in). The Government can continue with these centers for facilitating e-Learning support to the needed students.

A strategic planning is required to implement the second proposal. More focus should be given to the asynchronous mode learning via virtual classrooms than the live classes, as some students may not get access to device and internet on that particular time. Teachers can also use the recording facility to record an online class and post it in the classroom so that students who missed the live class can watch it at their convenience.

The ease of creating different types of assignments within the classrooms enables teachers to carry out continuous evaluation. Virtual classrooms support subjective and objective evaluations using docs and forms. Teachers can resend assignments back to the students as many as times as she wishes. There is also provision for collaborative works in the assignments. For time-bound assessment a new solution is required for students who often get disconnected. This is described is details in the next section.

\section{PROPOSED SOLUTION FOR TIME-BOUND ASSIGNMENTS}

In recent times many Online Examination System (OLE) are proposed with many innovative features (Younis \& Hussein, 2015),(Zhenming et al., 2003),(Vasupongayya et al., 2010),(Sheshadri et al., 2011), but most of them have not paid much attention towards addressing issues like poor network or losing connectivity during the examination. Most of these proposed OLEs are web-based while some of them are app based and hybrid. In web based OLEs, the server side contains server agent and database and the client side is consists of Graphical User Interface (GUI) and client side scripting. Younis et al. (Younis \& Hussein, 2015) proposed an OLE with resumption capability in case of connection failure. The examination is conducted locally at client side with help of a client agent, with all questions and answers being stored in a temporary file to facilitate the resumption capability in case of any network failure. In (Zhenming et al., 2003), Zhenming et al. introduced is a web-based testing interface which used Distributed Component Object Model (DCOM) model instead of client server framework. It facilitates auto-installation, real time monitoring and timer control.

Considering the fact that many students face connectivity issues and may not be able to participate in online examination or time-bound assignments, there is always a need for a solution which enables students to write for exam in offline mode without bypassing the time constraint of OLE. However, most of the above reviewed systems suffer in two aspects, vulnerable resources and only one-time synchronization. The security aspect is compromised by keeping important resources like answers and timer information at client place. On the other hand only one-time synchronization between server and client's timer makes it difficult to implement system locking and partial submission when the exam time is over.

Many researchers (Litayem et al., 2015)(Chakraborty \& Chattopadhyay, 2020) have also proposed quiz/assessment tool that serves heterogeneous platforms using hybrid android and web technologies. They support both offline and time-bound assignment but not at the same time. Form based quiz/ assignment like Google form, are easy to use and deploy for simple text based MCQ. For science and technology subjects equation and diagrams may be added separately as attachment. Summative assignments are technically easier to handle for both teachers and students, where teacher can attach the question in the form and students can response within the allotted space within the form or 


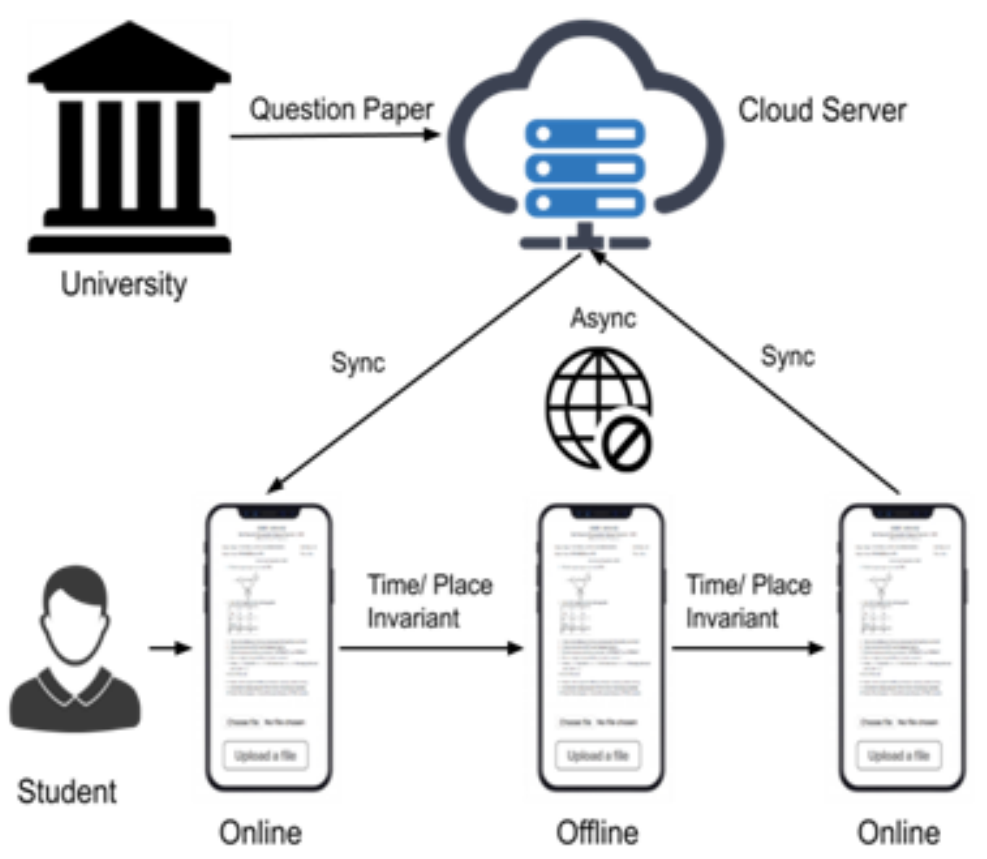

attach their response as separate files. However, in both the cases, time-bound submission is hard to implement for students with poor network connectivity but at the same time it cannot be ignored completely for its importance in summative evaluation. The challenges with time-bound assignments are summarized as:

- Students may lose connectivity during exam

- Form based MCQ are web-applications hence browser dependent

- Complexity in setting questions with equation, formula, diagram, chart and figure

- No provision for local storage in case of failure in real-time submission

Figure 3 depicts the architecture of our proposal. The University would host the question papers along with scheduled timing to the cloud server. The installed android app on the students' devices would get notified about this server upload and could be synchronized accordingly. This process has to be completed only once (preferably few days before the exam). Then the device may go offline and the android app would use the device clock for tracking the time. If the device happens to be connected to the network anytime, the clock would be synchronized. However, it would not be any problem, if it does not get connection. The app will unlock the question paper on due time and would be locked again after scheduled time period for the exam is over. During the exam, students must write answer on blank sheets, take snap of the pages using mobile camera, make pdf using the app, and submit within the app before the app locks itself. Student's response would be stored locally on the mobile storage in encrypted form. After the end of the exam, the app will allow its user only to upload the response back to the server, leaving all the other menus disabled. The authority may allow certain time period (say 2-5 days) for the student to get the device connected back to the network so that the response can be finally uploaded to the server. 


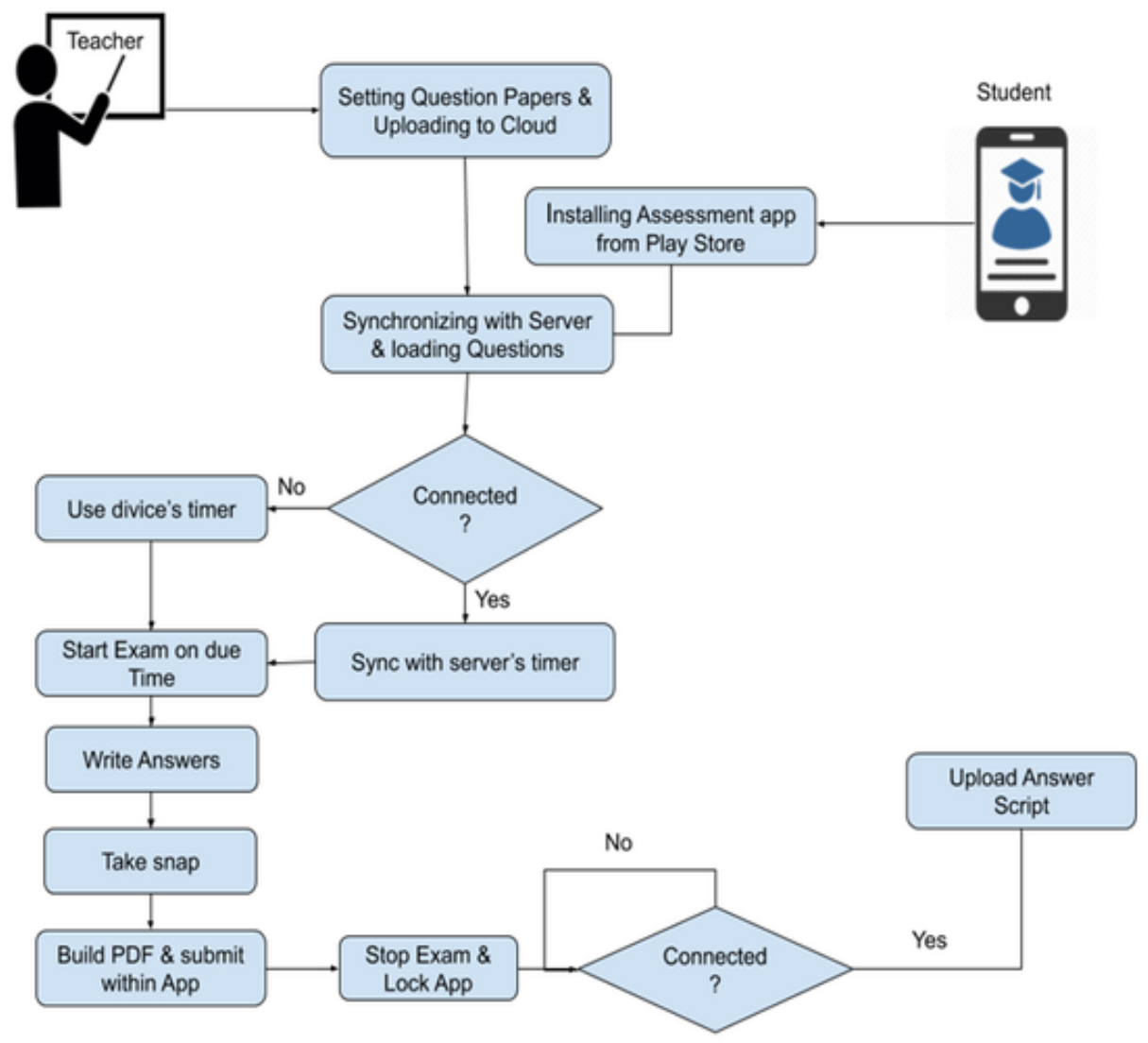

The flowchart of the working principle is shown in Figure 4. The novelty of the solution is that student can participate in time-bound exam/assignment even if the device is not connected to the internet. The requirement for connectivity comes only twice - once for getting the app loaded with question papers and synchronized with the server before the start of the exam, and secondly when student wants to upload the response back to the server. In both the cases the authority can set a safe time period of 2-5 days so that the student can make it convenient to get connected to the internet. The features of the proposed solution are listed as below:

- $\quad$ The mobile application (app) can control all the features within Android environment, hence no external dependency involved

- Two-time synchronization required, one before exam and one after exam

- Examination/assignment could be offline, response is stored locally

- Student's response would be locked after scheduled time

- Students should upload their response to the server whenever it gets connected to the network

\section{CONCLUSION}

In this paper the author explores the possibilities and challenges of online education in India through free e-learning platforms. Some popular products are compared with respect to two main components 
- asynchronous virtual classrooms and synchronous live meetings. It is found that SaaS based packages like 'G-Suite for education' or 'Office 365 education' could be better choice over integrating multiple services with LMS. A survey is done in order to understand the actual status of the students with respect to technical facilities. It is found that most of the students rely on mobile phones and mobile data for online learning. Based on the features available on the e-Learning platforms, this work proposed some strategic plan to ensure inclusivity of online education across all the sections of the society. The absence of any supportive tool for time-bound assignments/examination in the above discussed online platforms is identified. This paper also proposes a technical solution for the time-bound assignments/examination considering the issues related to poor internet bandwidth and network connectivity. However, since the survey is conducted on a small section of students, the proposed strategies may be biased or ad-hoc. With more data available from the entire country, the planning could be adjusted accordingly to overcome this limitation. Survey forms have also been sent to some of the Universities of the neighboring countries. We can present a comparative analysis of the situation once that data is available. The mobile app is currently being used in some of the colleges; we can further improve it based on its performance evaluation from the feedback report. These are the future scopes of this work.

- This research received no specific grant from any funding agency in the public, commercial, or not-for-profit sectors.

- There is no conflict of interest to disclose. 


\section{REFERENCES}

Aberdour, M. (2011). Virtual classrooms: an overview. cedma-europe.org

Bao, W. (2020). COVID-19 and online teaching in higher education: A case study of Peking University. Human Behavior and Emerging Technologies, 2(2), 113-115. doi:10.1002/hbe2.191 PMID:32510042

1Chakraborty, D., \& Chattopadhyay, M. (2020). Assignment Tracking on Android Platform. In Information and Communication Technology for Sustainable Development (pp. 491-499). Springer. doi:10.1007/978-98113-7166-0_49

Crawford, J., Butler-Henderson, K., Rudolph, J., Malkawi, B., Glowatz, M., Burton, R., \& Lam, S. et al. (2020). COVID-19: 20 countries' higher education intra-period digital pedagogy responses. Journal of Applied Learning \& Teaching, 3(1), 1-20.

Farrow, R. (2019). Massive Open Online Courses for Employability, Innovation and Entrepreneurship: a Rapid Assessment of Evidence. Academic Press.

Indian National Commission for Cooperation With UNESCO Response to COVID 19. (n.d.). https://www.mhrd. gov.in/indian-national-commission-cooperation-unesco-responding-covid-19

Kapasia, N., Paul, P., Roy, A., Saha, J., Zaveri, A., Mallick, R., Barman, B., Das, P., \& Chouhan, P. (2020). Impact of lockdown on learning status of undergraduate and postgraduate students during COVID-19 pandemic in West Bengal, India. Children and Youth Services Review, 116, 105194. doi:10.1016/j.childyouth.2020.105194 PMID:32834270

Litayem, N., Dhupia, B., \& Rubab, S. (2015). Review of cross-platforms for mobile learning application development. International Journal of Advanced Computer Science and Applications, 6(1). Advance online publication. doi:10.14569/IJACSA.2015.060105

Ministry of Health and Family Welfare. (n.d.). Government of India. https://www.mohfw.gov.in/

Ouadoud, M., Chkouri, M. Y., Nejjari, A., \& El Kadiri, K. E. (2016, October). Studying and comparing the free e-learning platforms. In 2016 th IEEE International Colloquium on Information Science and Technology (CiSt) (pp. 581-586). IEEE. doi:10.1109/CIST.2016.7804953

Phutela, N., \& Dwivedi, S. (2020). A qualitative study of students' perspective on e-learning adoption in India. Journal of Applied Research in Higher Education, 12(4), 545-559. doi:10.1108/JARHE-02-2019-0041

Sathish, M. T., Sornaganesh, V., Sudha, G., \& Chellama, A. V. (n.d.). A study on shift of traditional classroom methods to online teaching methods in higher education scenario during lockdown. Academic Press.

Sheshadri, , Reddy, , \& Kumar, . (2011). Web-Based-Secure Online Non-Choice-Based Examination System (WONES) using Cryptography. International Journal on Computer Science and Engineering, 3 (10), $3383-3393$.

Sintema, E. J. (2020). Effect of COVID-19 on the performance of grade 12 students: Implications for STEM education. Eurasia Journal of Mathematics, Science and Technology Education, 16(7), em1851. doi:10.29333/ ejmste/7893

Vasupongayya, S., Kamolphiwong, T., Kamolphiwong, S., \& Sae-Wong, S. (2010). Interactive Examination Management System. Proceedings of the 2nd IEEE/IACSIT International Conference on Education Technology and Computer (ICETC), 2, 55-59.

World Bank's United Nations Population Division's World Urbanization Prospects. (2018). Revision. https:// data.worldbank.org/indicator/SP.RUR.TOTL.ZS

Younis, M. I., \& Hussein, M. S. (2015). Construction of an online examination system with resumption and randomization capabilities. International Journal of Computing, 4(2).

Zhenming, Y., Liang, Z., \& Guohua, Z. (2003, November). A novel web-based online examination system for computer science education. In 33rd ASEE/IEEE Frontiers in Education Conference (pp. 5-8). doi:10.1109/ FIE.2003.1265999 